\title{
SUATU KAJIAN TENTANG FUNGSI SKOR DIPERUMUM YANG BARU DARI HIMPUNAN KABUR INTUISIONISTIK BERNILAI INTERVAL DAN APLIKASINYA
}

\author{
IRHAM MAULANA PUTRA, MONIKA RIANTI HELMI \\ Program Studi S1 Matematika, \\ Fakultas Matematika dan Ilmu Pengetahuan Alam, Universitas Andalas, \\ Kampus UNAND Limau Manis Padang, Indonesia. \\ email : irhamaulanaputra@gmail.com
}

Diterima 9 Maret 2019 Direvisi 7 April 2019 Dipublikasikan 7 Mei 2019

\begin{abstract}
Abstrak. Pengambilan keputusan multi kriteria (Multi Criteria Decision Making/MCDM) adalah salah satu proses untuk menemukan pengambilan keputusan alternatif yang optimal dengan beberapa kriteria atau atribut. Tetapi pada pengambilan keputusan dalam kehidupan nyata, tujuan dan batasan umumnya tidak tepat atau tidak jelas karena tidak dapat diperkirakan dengan nilai numerik yang tepat. Untuk mengatasi permasalahan tersebut, teori himpunan kabur (Fuzzy Set/FS) yang diperkenalkan oleh L.A Zadeh [10] telah banyak digunakan untuk menangani ketidakpastian dan ketidakjelasan suatu data. Teori himpunan kabur intuisionistik (Intuitionistik Fuzzy Set/IFS) [1] merupakan perluasan dari teori himpunan kabur. Ada dua topik penting dalam teori himpunan kabur Intuisionistik bernilai interval, yaitu MCDM dan perluasan fungsi skor yang telah banyak diteliti secara luas oleh peneliti dari berbagai sudut pandang. Dalam tulisan ini Penulis ingin mengkaji kembali bagaimana menyelesaikan masalah pengambilan keputusan multi-kriteria dengan menggunakan fungsi skor yang ditingkatkan yang diperumum dengan menggunakan bobot yang disebut atribut untuk mendapatkan keputusan yang tepat dan sesuai dengan waktu yang singkat.
\end{abstract}

Kata Kunci: Himpunan Kabur, Himpunan Kabur Intuisionistik, Fungsi skor

\section{Pendahuluan}

Ada dua topik penting dalam teori himpunan kabur, yaitu MCDM dan perluasan fungsi skor yang telah banyak diteliti secara luas oleh peneliti dari berbagai sudut pandang. Wang dan Wang [5] memperkenalkan metode untuk menyelesaikan MCDM pada IVIFS dan informasi tentang bobot atribut yang tidak diketahui. Xu dan Chen [6,7] mengusulkan fungsi skor untuk membuat peringkat pada IVIFS. Xu [8] mengembangkan berberapa operasi pada IVIFS untuk masalah MCDM dengan menggunakan fungsi skor. Bai [3] memperkenalkan fungsi skor yang ditingkatkan untuk menentukan peringkat yang efektif pada IVIFS berdasarkan fungsi skor dengan bobot kriteria yang diketahui. Garg [4] mendefinisikan suatu fungsi skor yang 
diperumum yang merupakan perumuman dari teori fungsi skor yang telah didefinisikan oleh Bai [3].

Dalam berberapa kasus, metode dalam fungsi skor pada IVIFS tidak memberikan informasi yang akurat. Oleh karena itu, ada suatu fungsi skor yang ditingkatkan untuk menangani kekurangan fungsi skor dan memberikan informasi yang memadai kepada seseorang dalam pengambilan keputusan. Selain itu, urutan peringkat akhir sangat bergantung pada suatu bobot yang disebut atribut, karenanya penilaian pada bobot atribut memainkan peranan penting dalam proses pengambilan keputusan. Dengan demikian, sangat penting untuk menemukan bobot atribut yang tepat yang akan membantu pengambil keputusan untuk mendapatkan keputusan yang tepat dan sesuai dalam waktu yang singkat.

\section{Landasan Teori}

Definisi 2.1. [10] Misalkan X suatu himpunan semesta yang tak kosong. Himpunan kabur (FS) A atas $X$ didefinisikan sebagai:

$$
A=\left\{\left\langle x, \mu_{A}(x)\right\rangle ; x \in X\right\},
$$

dimana $\mu_{A}: X \rightarrow[0,1]$, dan $\mu_{A}(x)$ disebut nilai keanggotaan atas $X$ pada himpunan kabur $A$.

Definisi 2.2. [1] Misalkan X adalah himpunan semesta yang tak kosong. Himpunan kabur intuitionistik (IFS) $A$ atas $X$ adalah:

$$
A=\left\{\left\langle x, \mu_{A}(x), \nu_{A}(x)\right\rangle ; x \in X\right\},
$$

dimana, $\mu_{A}, \nu_{A}: X \rightarrow[0,1] . \mu_{A}(x), \nu_{A}(x)$ berturut-turut menyatakan nilai keanggotaan dan nilai ketidakanggotaan atas $X$ pada himpunan A. Selanjutnya untuk setiap $x \in X$ berlaku:

$$
0 \leqslant \mu_{A}(x)+\nu_{A}(x) \leqslant 1
$$

dan $\pi_{A}(x)=1-\mu_{A}(x)-\nu_{A}(x)$ disebut nilai keragu-raguan atas $X$ pada IFS $A$, artinya $\pi_{A}(x)$ menyatakan ketidaktahuan apakah $x$ mempunyai nilai keanggotaan atau tidak pada IFS dengan $\pi_{A}: X \rightarrow[0,1]$ untuk setiap $x \in X$. Kemudian Komplemen $A^{c}$ dari $A$ didefinisikan sebagai

$$
A^{c}=\left\{\left\langle x, \nu_{A}(x), \mu_{A}(x)\right\rangle ; x \in X\right\} .
$$

Suatu bilangan kabur intuisionistik (Intuitionistic Fuzzy Number/IFN) $\widetilde{A}$ atas $x \in$ $X$ didefinisikan sebagai

$$
\widetilde{A}=\left\langle\left[\mu_{A}\left(x_{i}\right), \nu_{A}\left(x_{i}\right)\right]\right\rangle \text { dengan } x_{i} \in X, i=1,2, \cdots
$$

$\mathrm{Xu}$ [8] mendefinisikan suatu operasi untuk bilangan kabur intuisionistik (intuitionistic fuzzy number $\left./ \mathrm{IFN}) \alpha=\langle\mu, v\rangle, \alpha_{1}=\left\langle\mu_{1}, v_{1}\right\rangle, \alpha_{2}=\left\langle\mu_{2}, v_{2}\right\rangle, \lambda\right\rangle 0$ seperti berikut:

(1) $\alpha_{1} \oplus \alpha_{2}=\left\langle 1-\left(1-\mu_{1}\right)\left(1-\mu_{2}\right), v_{1} v_{2}\right\rangle$.

(2) $\alpha_{1} \otimes \alpha_{2}=\left\langle\mu_{1} \mu_{2}, 1-\left(1-v_{1}\right)\left(1-v_{1}\right)\right\rangle$. 
(3) $\lambda \alpha=\left\langle 1-(1-\mu)^{\lambda}, v^{\lambda}\right\rangle$.

(4) $\alpha^{\lambda}=\left\langle\mu^{\lambda}, 1-(1-v)^{\lambda}\right\rangle$.

Berdasarkan operasi di atas, operator bobot rata-rata himpunan kabur intuisionistik (Intuitionistik Fuzzy Weighted Average/IFWA) [8] didefinisikan untuk menggabungkan himpunan IFN sebagai berikut:

$$
\begin{aligned}
I F W A\left(\alpha_{1}, \alpha_{2}, \cdots, \alpha_{n}\right) & =\omega_{1} \alpha_{1} \oplus \omega_{2} \alpha_{2} \oplus \cdots \oplus \omega_{n} \alpha_{n} \\
& =\left\langle 1-\prod_{i=1}^{n}\left(1-\mu_{i}\right)^{\omega_{i}}, \prod_{i=1}^{n}\left(v_{i}\right)^{\omega_{i}}\right\rangle,
\end{aligned}
$$

dimana $\omega=\left(\omega_{1}, \omega_{2}, \cdots, \omega_{n}\right)$ adalah vektor bobot standar.

Berdasarkan definisi operator dari IFWA, Zhao dkk [11] memperkenalkan operator IFWA yang diperumum yaitu Generalized Intuitionistic Fuzzy Weighted Average dan dilambangkan oleh operator GIFWA yang didefinisikan sebagai berikut:

$$
\begin{aligned}
& \operatorname{GIFWA}\left(\alpha_{1}, \alpha_{2}, \cdots, \alpha_{n}\right)=\left(\omega_{1} \alpha_{1}^{\lambda} \oplus \omega_{2} \alpha_{2}^{\lambda} \oplus \cdots \oplus \omega_{n} \alpha_{n}^{\lambda}\right)^{\frac{1}{\lambda}} \\
= & \left\langle\left(1-\prod_{j=1}^{n}\left(1-\mu_{i}^{\lambda}\right)^{\omega_{j}}\right)^{\frac{1}{\lambda}}, 1-\left(1-\prod_{j=1}^{n}\left(1-\left(1-v_{j}\right)^{\lambda}\right)^{\omega_{j}}\right)^{\frac{1}{\lambda}}\right\rangle,
\end{aligned}
$$

dimana $\lambda>0$ merupakan bilangan riil.

Dari operator ini, diperoleh bahwa operator IFWA adalah kasus khusus dari ope-rator GIFWA sehingga operasi ini banyak digunakan oleh para peneliti untuk menggabungkan berberapa tingkat kepentingan yang berbeda tetapi masih memiliki beberapa kelemahan.

Contoh 2.3. Misalkan diberikan empat buah IFN $\alpha_{1}=\langle 0.70,0.00\rangle, \alpha_{2}=$ $\langle 0.65,0.30\rangle, \alpha_{3}=\langle 0.30,0.60\rangle, \alpha_{4}=\langle 0.70,0.30\rangle$, dan $\omega=(0.2,0.3,0.4,0.1)$ adalah vektor bobot standar dari IFN, untuk nilai $\lambda$ yang berbeda dengan menggunakan operator GIFWA diperoleh sebagai berikut:

(1) Untuk $\lambda=1$, GIFWA $\left(\alpha_{1}, \alpha_{2}, \alpha_{3}, \alpha_{4}\right)=\langle 0.5590,0\rangle$,

(2) Untuk $\lambda=2$, GIFWA $\left(\alpha_{1}, \alpha_{2}, \alpha_{3}, \alpha_{4}\right)=\langle 0.5768,0\rangle$,

(3) Untuk $\lambda=10, \operatorname{GIFWA}\left(\alpha_{1}, \alpha_{2}, \alpha_{3}, \alpha_{4}\right)=\langle 0.6456,0\rangle$.

Dengan demikian, telah dianalisis bahwa hasil dari operator GIFWA tidak dapat digunakan, karena nilai ketidakanggotaan dari hasil operator adalah nol tidak tergantung dengan nilai parameternya. Hal ini disebabkan karena nilai ketidakanggotaan dari $\alpha_{1}$ sama dengan nol. Oleh karena itu, jika ada suatu nilai ketidakanggotaan dari IFN yang bernilai nol maka tidak dapat menggabungkan berberapa IFN menggunakan operator GIFWA.

Yu [9] memodifikasi operasi yang didefinisikan oleh Xu [8] sebelumnya dengan mendefinisikan operasi::

(1) $\alpha_{1} \oplus \alpha_{2}=\left\langle 1-\left(1-\mu_{1}\right)\left(1-\mu_{2}\right),\left(1-\mu_{1}\right)\left(1-\mu_{2}\right)-\left(1-\left(\mu_{1}+v_{1}\right)\right)\left(1-\left(\mu_{2}+v_{2}\right)\right\rangle\right.$.

(2) $\alpha_{1} \otimes \alpha_{2}=\left\langle\left(1-v_{1}\right)\left(1-v_{2}\right)-\left(1-\left(\mu_{1}+v_{1}\right)\right)\left(1-\left(\mu_{2}+v_{2}\right)\right), 1-\left(1-v_{1}\right)\left(1-v_{2}\right)\right\rangle$.

(3) $\lambda \alpha=\left\langle 1-(1-\mu)^{\lambda},(1-\mu)^{\lambda}-(1-\mu-v)^{\lambda}\right\rangle$.

(4) $\alpha^{\lambda}=\left\langle(1-v)^{\lambda}-(1-\mu-v)^{\lambda}, 1-(1-v)^{\lambda}\right\rangle$. 
Berdasarkan operasi di atas, Yu [9] mendefinisikan operator bobot rata-rata interaktif himpunan kabur intuisionistik yang diperumum (Generalized Intui-tionistic Fuzzy Interactive Weighted Average/GIFIWA) untuk menggabungkan himpunan IFN $\left(\alpha_{1}, \alpha_{2}, \cdots, \alpha_{n}\right)$ sebagai berikut:

Definisi 2.4. [9] Operator bobot rata-rata interaktif himpunan kabur intuisionistik yang diperumum (Generalized Intui-tionistic Fuzzy Interactive Weighted Average/GIFIWA) untuk menggabungkan himpunan IFN $\left(\alpha_{1}, \alpha_{2}, \cdots, \alpha_{n}\right)$ adalah:

$$
\begin{aligned}
\operatorname{GIFIWA}\left(\alpha_{1}, \alpha_{2}, \cdots, \alpha_{n}\right)= & \left(\omega_{1} \alpha_{1}^{\lambda} \oplus \omega_{2} \alpha_{2}^{\lambda} \oplus \cdots \oplus \omega_{n} \alpha_{n}^{\lambda}\right)^{\frac{1}{\lambda}} \\
= & \left\langle\left( 1-\prod_{i=1}^{n}\left(1-\left(1-v_{i}\right)^{\lambda}+\left(1-\left(\mu_{i}+v_{i}\right)\right)^{\lambda}\right)^{\omega_{i}}\right.\right. \\
& \left.+\prod_{i=1}^{n}\left(1-\left(\mu_{i}+v_{i}\right)\right)^{\lambda \omega_{i}}\right)^{\frac{1}{\lambda}}-\prod_{i=1}^{n}\left(1-\left(\mu_{i}+v_{i}\right)\right)^{\omega_{i}}, \\
& 1-\left(1-\prod_{i=1}^{n}\left(1-\left(1-v_{i}\right)^{\lambda}+\left(1-\left(\mu_{i}+v_{i}\right)^{\lambda}\right)^{\omega_{i}}\right.\right. \\
& \left.\left.+\prod_{i=1}^{n}\left(1-\left(\mu_{i}+v_{i}\right)\right)^{\lambda \omega_{i}}\right)\right\rangle .
\end{aligned}
$$

Pada operator bobot rata-rata GIFIWA, ketika $\lambda=1$ maka operator GIFIWA akan sama dengan operator GIFWA.

Pada Contoh 2.3 operator bobot rata-rata GIFIWA dengan nilai-nilai $\lambda$ yang berbeda maka diperoleh nilai hasil operatornya adalah:

(1) $\lambda=1, \operatorname{GIFIWA}\left(\alpha_{1}, \alpha_{2}, \alpha_{3}, \alpha_{4}\right)=\langle 0.5590,0.4410\rangle$,

(2) Untuk $\lambda=2$, GIFIW $A\left(\alpha_{1}, \alpha_{2}, \alpha_{3}, \alpha_{4}\right)=\langle 0.7464,0.2536\rangle$,

(3) Untuk $\lambda=10$, GIFIW $A\left(\alpha_{1}, \alpha_{2}, \alpha_{3}, \alpha_{4}\right)=\langle 0.9907,0.0093\rangle$.

Dengan demikian, hasil dari nilai operatornya berdasarkan operator GIFIWA dapat digunakan.

Definisi 2.5. [2] Misalkan $X$ adalah himpunan semesta yang tak kosong dan int $(0,1)$ menunjukkan himpunan dari semua subinterval tertutup dari interval $[0,1]$. Sebuah himpunan kabur intuitionistik bernilai interval (Interval Value Intuitionistic Fuzzy Set/IVIFS) A atas X adalah:

$$
A=\left\{\left\langle x, \mu_{A}(x), \nu_{A}(x)\right\rangle ; x \in X\right\},
$$

dimana

$$
\mu_{A}: X \rightarrow \operatorname{int}(0,1) \text { dan } \nu_{A}: X \rightarrow \operatorname{int}(0,1),
$$

Interval $\mu_{A}(x)$ dan $\nu_{A}(x)$ masing-masing menujukkan nilai keanggotaan dan ketidakanggotaan atas $X$ pada A. Jika dimisalkan:

$$
\mu_{A}(x)=\left[\mu_{A}^{-}(x), \mu_{A}^{+}(x)\right] \text { dan } \nu_{A}(x)=\left[\nu_{A}^{-}(x), \nu_{A}^{+}(x)\right],
$$


$m a k a$

$$
A=\left\{\left\langle x,\left[\mu_{A}^{-}(x), \mu_{A}^{+}(x)\right],\left[\nu_{A}^{-}(x), \nu_{A}^{+}(x)\right]\right\rangle ; x \in X\right\},
$$

dengan kondisi

$$
0 \leqslant \mu_{A}^{+}(x)+\nu_{A}^{+}(x) \leqslant 1
$$

dimana $\mu_{A}^{-}(x), \mu_{A}^{+}(x)$ berturut turut menyatakan batas bawah terbesar dan batas atas terkecil dari $\mu_{A}(x)$ dan $\nu_{A}^{-}(x), \nu_{A}^{+}(x)$ berturut turut menyatakan batas bawah terbesar dan batas atas terkecil dari $\nu_{A}(x)$.

Kemudian interval

$$
\left[1-\mu_{A}^{+}(x)-\nu_{A}^{+}(x), 1-\mu_{A}^{-}(x)-\nu_{A}^{-}(x)\right]
$$

disingkat dengan $\left[\pi_{A}^{-}(x), \pi_{A}^{+}(x)\right]$ dan dilambangkan dengan $\pi_{A}(x)$ merupakan indeks intuitionistik bernilai interval dari $X$ pada $A$.

Definisi 2.6. [4] Suatu bilangan kabur intuisionistik bernilai interval (Interval Value Intuitionistic Fuzzy Number/IVIFN) $\widetilde{A}$ atas $x \in X$ didefinisikan sebagai

$$
\widetilde{A}=\left\langle\left[\mu_{A}^{-}(x), \mu_{A}^{+}(x)\right],\left[\nu_{A}^{-}(x), \nu_{A}^{+}(x)\right]\right\rangle
$$

Suatu bilangan kabur intuisionistik bernilai interval $\alpha=\left\langle\alpha_{1}, \alpha_{2}, \cdots, \alpha_{n}\right\rangle$, dan $\omega=$ $\left(\omega_{1}, \omega_{2}, \cdots, \omega_{n}\right)$ merupakan vektor bobot standar.

Definisi 2.7. [4] Misalkan $A_{m \times n}\left(x_{i j}\right)=\left(\left\langle\left[a_{i j}, b_{i j}\right],\left[c_{i j}, d_{i j}\right]\right\rangle\right)$ adalah suatu matriks dengan $x_{i j}=\left\langle\left[a_{i j}, b_{i j}\right],\left[c_{i j}, d_{i j}\right]\right\rangle$, dimana $\left[a_{i j}, b_{i j}\right]$ adalah nilai keanggotaan yang menunjukkan objek ke-i dan kriteria ke-j, sedangkan $\left[c_{i j}, d_{i j}\right]$ adalah nilai ketidakanggotaan yang menunjukan objek ke-i dan kriteria ke-j dengan $i=1,2, \cdots, m$ dan $j=1,2, \cdots, n$. Operator bobot rata-rata interaktif yang diperumum pada himpunan kabur intuisionistik bernilai interval (Generalized Interval Value Intuitionistic Fuzzy Interactive Weighted Average/GIVIFIWA) didefinisikan sebagai berikut:

$$
\begin{aligned}
\operatorname{GIVIFIWA}\left(\alpha_{1}, \alpha_{2}, \cdots, \alpha_{n}\right) & =\left(\omega_{1} \alpha_{1}^{\lambda} \oplus \omega_{2} \alpha_{2}^{\lambda} \oplus \cdots \oplus \omega_{n} \alpha_{n}^{\lambda}\right)^{\frac{1}{\lambda}} \\
& =<\left[A_{i}, B_{i}\right],\left[C_{i}, D_{i}\right]>
\end{aligned}
$$

dimana

$$
\begin{aligned}
A_{i}= & \left(1-\prod_{j=1}^{n}\left(1-\left(1-c_{i j}\right)^{\lambda}+\left(1-\left(a_{i j}+c_{i j}\right)\right)^{\lambda}\right)^{\omega_{j}}+\prod_{j=1}^{n}\left(1-\left(a_{i j}+c_{i j}\right)\right)^{\lambda \omega_{j}}\right)^{\frac{1}{\lambda}} \\
& -\prod_{j=1}^{n}\left(1-\left(a_{i j}+c_{i j}\right)\right)^{\omega_{j}}
\end{aligned}
$$




$$
\begin{aligned}
B_{i}= & \left(1-\prod_{j=1}^{n}\left(1-\left(1-d_{i j}\right)^{\lambda}+\left(1-\left(b_{i j}+d_{i j}\right)\right)^{\lambda}\right)^{\omega_{j}}+\prod_{j=1}^{n}\left(1-\left(b_{i j}+d_{i j}\right)\right)^{\lambda \omega_{j}}\right)^{\frac{1}{\lambda}} \\
& -\prod_{j=1}^{n}\left(1-\left(b_{i j}+d_{i j}\right)\right)^{\omega_{j}} ; \\
C_{i}= & 1-\left(1-\prod_{j=1}^{n}\left(1-\left(1-c_{i j}\right)^{\lambda}+\left(1-\left(a_{i j}+c_{i j}\right)^{\lambda}\right)^{\omega_{j}}+\prod_{j=1}^{n}\left(1-\left(a_{i j}+c_{i j}\right)^{\lambda} \omega_{j}\right)^{\frac{1}{\lambda}} ;\right.\right. \\
D_{i}= & 1-\left(1-\prod_{j=1}^{n}\left(1-\left(1-d_{i j}\right)^{\lambda}+\left(1-\left(b_{i j}+d_{i j}\right)^{\lambda}\right)^{\omega_{j}}+\prod_{j=1}^{n}\left(1-\left(b_{i j}+d_{i j}\right)^{\lambda} \omega_{j}\right)^{\frac{1}{\lambda}},\right.\right.
\end{aligned}
$$

dan $\lambda>0$.

Untuk membandingkan dua atau lebih IVIFN, berberapa metode telah dibahas oleh berbagai penulis. Dalam hal fungsi skor untuk IVIFN $A=\langle[a, b],[c, d]\rangle$ dengan $\mu_{A}(x)=[a, b]$, dan $\nu_{A}(x)=[c, d]$ yang diberikan sebagai berikut:

(i) Fungsi skor $[6]$

$$
S(A)=\frac{a+b-c-d}{2}, S(A) \in[-1,1]
$$

(ii) Peningkatan fungsi skor [3]

$$
I(A)=\frac{a+a(1-a-c)+b+b(1-b-d)}{2}, I(A) \in[0,1] .
$$

\section{Pembahasan}

\subsection{Perumuman dari Fungsi Skor yang Ditingkatkan (Generalized Improved Score Function)}

Definisi 3.1. [4] Misalkan $A=\langle[a, b],[c, d]\rangle$ adalah suatu IVIFN, suatu fungsi skor yang ditingkatkan yang diperumum (GIS) dari nilai himpunan kabur intuisionistik bernilai interval dengan bobot yang tidak diketahui didefini-sikan sebagai:

$$
G I S(A)=\frac{a+b}{2}+k_{1} a(1-a-c)+k_{2} b(1-b-d), G I S(A) \in[0,1],
$$

dimana $k_{1}+k_{2}=1, k_{1}, k_{2} \geq 0$.

Ketika $k_{1}=k_{2}=\frac{1}{2}$, maka fungsi GIS akan menjadi fungsi skor yang ditingkatkan (Improved Score Function/I) yaitu

$$
I(A)=\frac{a+a(1-a-c)+b+b(1-b-d)}{2}, I(A) \in[0,1] .
$$

Definisi 3.2. [4] Misalkan $A_{1}=\left\langle\left[a_{1}, b_{1}\right],\left[c_{1}, d_{1}\right]\right\rangle, A_{2}=\left\langle\left[a_{2}, b_{2}\right],\left[c_{2}, d_{2}\right]\right\rangle$ adalah dua bilangan interval atas $[0,1]$. Misalkan " $\leq$ merupakan suatu hubungan pada $\operatorname{int}(0,1)$ yang didefinisikan sebagai: $\left\langle\left[a_{1}, b_{1}\right],\left[c_{1}, d_{1}\right]\right\rangle \leq\left\langle\left[a_{2}, b_{2}\right],\left[c_{2}, d_{2}\right]\right\rangle$ jika dan hanya jika $a_{1} \leq a_{2}, b_{1} \leq b_{2}, c_{1} \geq c_{2}$ dan $d_{1} \geq d_{2}$.

Teorema 3.3. [4] Jika $\alpha_{1} \neq \alpha_{2}$ dengan $\alpha_{1}=\left\langle\left[a_{1}, b_{1}\right],\left[c_{1}, d_{1}\right]\right\rangle$ dan $\alpha_{2}=$ $\left\langle\left[a_{2}, b_{2}\right],\left[c_{2}, d_{2}\right]\right\rangle$ merupakan dua IVIFN dan $S\left(\alpha_{1}\right)=S\left(\alpha_{2}\right)$ maka GIS $\left(\alpha_{1}\right) \neq$ $G I S\left(\alpha_{2}\right)$. 
Fungsi skor yang diusulkan untuk peringkat dari nilai himpunan kabur intuisionistik bernilai interval memiliki sifat seperti berikut:

(1) Untuk setiap bilangan kabur intuisionistik bernilai interval $A=\langle[a, b],[c, d]\rangle$, berlaku $G I S(A) \in[0,1]$.

(2) Jika $A=\langle[0,0],[1,1]\rangle$ adalah suatu IVIFN, maka $G I S(A)=0$.

(3) Jika $A=\langle[1,1],[0,0]\rangle$ adalah suatu IVIFN, maka $G I S(A)=1$.

(4) Untuk suatu bilangan kabur $A=\langle a, 1-a\rangle$, maka $G I S(A)=a$.

\subsection{Pendekatan yang Diusulkan untuk Masalah MCDM pada IVIFS}

Misalkan $A=\left\{A_{1}, A_{2}, \cdots, A_{m}\right\}$ adalah suatu himpunan dari $m$ alternatif dan $G=\left\{G_{1}, G_{2}, \cdots, G_{n}\right\}$ adalah suatu himpunan dari $n$ kriteria dan bobot atribut tidak diketahui. Prosedur untuk menghitung MCDM dirangkum dalam langkahlangkah berikut:

(1) Mengkonstruksi matriks keputusan pada IVIFN.

Andaikan $D_{m \times n}\left(x_{i j}\right)=\left(\left\langle\left[a_{i j}, b_{i j}\right],\left[c_{i j}, d_{i j}\right]\right\rangle\right)$ adalah suatu matriks keputusan himpunan kabur intuisionistik, $\left[a_{i j}, b_{i j}\right] \subset[0,1],\left[c_{i j}, d_{i j}\right] \subset[0,1], b_{i j}+d_{i j} \leq$ $1, i=1,2, \cdots, m, j=1,2, \cdots, n$. Oleh karena itu, matriks keputusan IVIFN dinyatakan sebagai berikut:

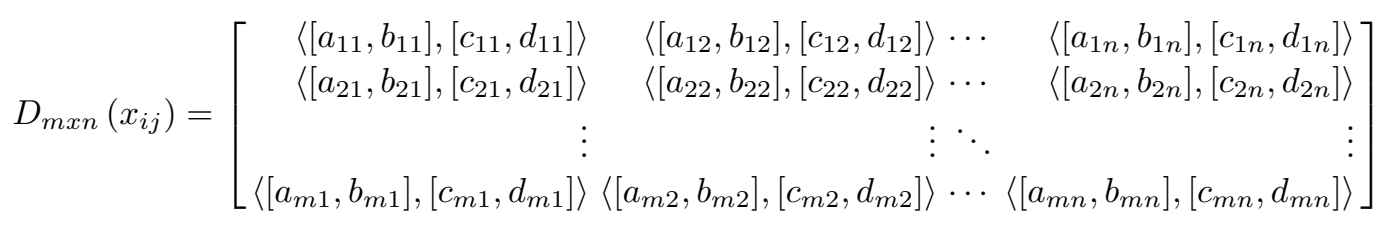

(2) Menentukan matriks GIS.

Berdasarkan fungsi skor yang ditingkatkan yang diperumum pada persamaan (3.1), akan diubah dari matriks keputusan kabur intuisionistik bernilai interval $D=\left(x_{i j}\right)_{m \times n}$ kedalam matriks skor $\left(G I S\left(r_{i j}\right)\right)_{m \times n}$. Oleh karena itu, skor IVIFN matriks $G I S\left(r_{i j}\right)$ dari $A_{i}$ pada $G_{j}$ dapat ditulis sebagai berikut.

$$
\left(G I S\left(r_{i j}\right)\right)_{m \times n}=\left[\begin{array}{cccc}
G I S\left(r_{11}\right) & G I S\left(r_{12}\right) & \cdots & G I S\left(r_{1 n}\right) \\
G I S\left(r_{21}\right) & G I S\left(r_{22}\right) & \cdots & G I S\left(r_{2 n}\right) \\
\vdots & \vdots & \ddots & \vdots \\
G I S\left(r_{m 1}\right) & G I S\left(r_{m 2}\right) & \cdots & G I S\left(r_{m n}\right)
\end{array}\right]
$$

(3) Menentukan bobot atribut.

Bobot atribut dalam pembuatan keputusan MCDM diklasifikasikan menjadi dua yaitu subjektif dan objektif. Salah satu pendekatan yang paling terkenal untuk menentukan bobot atribut yang bersifat objektif adalah dengan menggunakan metode entropi shannon, sehingga untuk bobot atribut dengan metode entropi shannon dapat didefinisikan sebagai:

$$
W_{j}=\frac{d_{j}}{\sum_{i=1}^{m} d_{j}}=\frac{1-k_{j}}{\sum_{i=1}^{m}\left(1-k_{j}\right)}=\frac{1-k_{j}}{n-\sum_{i=1}^{m} k_{j}},
$$


dengan derajat divergensi $d_{j}=1-k_{j}$, dimana $k_{j}=\sum_{i=1}^{m} G I S\left(r_{i j}\right), j=$ $1,2, \cdots, n$.

(4) Mengkonstruksi matriks keputusan himpunan kabur intuisionistik yang berbobot.

Matriks keputusan himpunan kabur intuisionistik yang berbobot dinyatakan sebagai $\vartheta_{i}=\left\langle\left[a_{i j}, b_{i j}\right],\left[c_{i j}, d_{i j}\right]\right\rangle$ untuk $i=1,2, \cdots, m, j=1,2, \cdots, n$, dengan menggunakan operator GIVIFIWA, sebagaimana didefinisikan pada persamaan (2.10)

(5) Menghitung nilai skor.

Nilai skor keseluruhan dari bilangan himpunan kabur intuisionistik gabungan $\vartheta_{i}, i=1,2, \cdots, m$. dapat dihitung dengan menggunakan fungsi skor yang diberikan dalam persamaan (3.1).

(6) Memberikan peringkat alternatif.

Pemberian peringkat alternatif dari $A_{i}=1,2, \cdots, m$ dan kemudian dipilih alternatif yang paling diinginkan sesuai dengan urutan menurun dari fungsi skor.

\subsection{Aplikasi pada Fungsi Skor yang Ditingkatkan Diperumum yang Baru dari Himpunan Kabur Intuisionistik Bernilai Interval}

Seseorang nelayan yang sudah lama mencari ikan di laut ingin beralih profesi menjadi seorang peternak. Nelayan tersebut ingin beternak hewan air tawar dengan empat kemungkinan alternatif, yaitu beternak ikan lele, beternak ikan nila, beternak ikan gurame, dan beternak udang yang masing-masing dinotasikan dengan $A_{1}, A_{2}, A_{3}, A_{4}$. Untuk mengambil suatu keputusan diberikan tiga kriteria oleh pembuat keputusan yaitu $C_{1}$ adalah analisis pasar, $C_{2}$ adalah analisis keuntungan dan $C_{3}$ adalah analisis resiko. Keempat kemungkinan alternatif $A_{i}$ dimana $i=1,2,3,4$. harus dievaluasi dengan menggunakan himpunan kabur intuisionistik bernilai internal oleh pembuat keputusan dengan memperhatikan ketiga kriteria yang telah diberikan, dicantumkan dalam sebuah matriks berikut:

$$
D_{4 \times 3}\left(x_{i j}\right)=\left[\begin{array}{l}
\langle[0.6,0.7],[0.2,0.3]\rangle\langle[0.6,0.7],[0.2,0.3]\rangle\langle[0.4,0.7],[0.1,0.2]\rangle \\
\langle[0.3,0.6],[0.3,0.4]\rangle\langle[0.5,0.6],[0.3,0.4]\rangle\langle[0.5,0.6],[0.1,0.3]\rangle \\
\langle[0.7,0.8],[0.1,0.2]\rangle\langle[0.6,0.7],[0.1,0.3]\rangle\langle[0.3,0.4],[0.1,0.2]\rangle \\
\langle[0.4,0.5],[0.3,0.4]\rangle\langle[0.4,0.6],[0.2,0.4]\rangle\langle[0.1,0.3],[0.5,0.6]\rangle
\end{array}\right] .
$$

Dari $G I S\left(x_{i j}\right), i=1,2,3,4 . j=1,2,3$. maka dapat dibentuk matriks seperti di bawah ini:

$$
\left(G I S\left(r_{i j}\right)\right)_{4 \times 3}=\left[\begin{array}{lll}
0.710 & 0.710 & 0.685 \\
0.510 & 0.600 & 0.680 \\
0.820 & 0.740 & 0.520 \\
0.535 & 0.580 & 0.235
\end{array}\right]
$$

Diperoleh,

$$
\omega_{1}=0.3642, \omega_{2}=0.3769, \omega_{3}=0.2590 .
$$


sehingga dapat ditulis sebagai berikut.

$$
\begin{array}{ll}
\vartheta_{1}=\langle[0.5557,0.7001],[0.1908,0.2999]\rangle, & \vartheta_{2}=\langle[0.4348,0.6000],[0.2572,0.4000]\rangle . \\
\vartheta_{3}=\langle[0.5836,0.6903],[0.1067,0.3097]\rangle, & \vartheta_{4}=\langle[0.3336,0.4985],[0.3062,0.5015]\rangle .
\end{array}
$$

Diperoleh:

$$
\operatorname{GIS}\left(\vartheta_{1}\right)=0.6983, \operatorname{GIS}\left(\vartheta_{2}\right)=0.5844, \operatorname{GIS}\left(\vartheta_{3}\right)=0.7273, \operatorname{GIS}\left(\vartheta_{4}\right)=0.4761 .
$$

\begin{tabular}{|c|c|c|c|c|c|}
\hline atribut & & & $k_{1}, k_{2}$ & & \\
\hline & $(0,1)$ & $\left(\frac{1}{4}, \frac{3}{4}\right)$ & $\left(\frac{1}{2}, \frac{1}{2}\right)$ & $\left(\frac{3}{4}, \frac{1}{4}\right)$ & $(1,0)$ \\
\hline$A_{1}$ & 0.6274 & 0.6629 & 0.6983 & 0.7336 & 0.7688 \\
\hline$A_{2}$ & 0.5171 & 0.5508 & 0.5844 & 0.6178 & 0.6512 \\
\hline$A_{3}$ & 0.6362 & 0.6818 & 0.7273 & 0.7728 & 0.8181 \\
\hline$A_{4}$ & 0.4143 & 0.4452 & 0.4761 & 0.5070 & 0.5379 \\
\hline rangking & $(3124)$ & $(3124)$ & $(3124)$ & $(3124)$ & $(3124)$ \\
\hline
\end{tabular}

Tabel 3.3.1. Nilai $k_{1}$ dan $k_{2}$

\section{Kesimpulan}

Berdasarkan uraian sebelumnya dapat disimpulkan bahwa:

(1) Fungsi skor yang ditingkatkan yang diperumum merupakan pengembangan dari fungsi skor yang telah diperkenalkan oleh Bai [3] yang didefinisikan sebagai

$$
G I S(A)=\frac{a+b}{2}+k_{1} a(1-a-c)+k_{2} b(1-b-d), \operatorname{GIS}(A) \in[0,1],
$$

dimana $k_{1}+k_{2}=1, k_{1}, k_{2} \geq 0$, dengan $A=\langle[a, b],[c, d]\rangle$ suatu bilangan kabur intuisionistik bernilai interval.

(2) Ketika $k_{1}=k_{2}=\frac{1}{2}$, maka fungsi GIS akan menjadi fungsi skor yang ditingkatkan yaitu

$$
I(A)=\frac{a+a(1-a-c)+b+b(1-b-d)}{2}, I(A) \in[0,1] .
$$

(3) Perluasan fungsi skor yang ditingkatkan dan diperumum dapat didefinisikan sebagai berikut:

Misalkan $A=\left\{A_{1}, A_{2}, \cdots, A_{m}\right\}$ suatu himpunan alternatif $m$ dan $G=$ $\left\{G_{1}, G_{2}, \cdots, G_{n}\right\}$ suatu himpunan dari $n$ kriteria dan bobot atribut yang tidak diketahui yang didefinisikan sesuai dengan kriteria $G_{j}$ sebagai berikut:

$$
W_{j}=\frac{d_{j}}{\sum_{i=1}^{m} d_{j}}=\frac{1-k_{j}}{\sum_{i=1}^{m}\left(1-k_{j}\right)}=\frac{1-k_{j}}{n-\sum_{i=1}^{m} k_{j}},
$$


dengan derajat divergensi $\left(d_{j}\right)$ didefinisikan sebagai $\left(d_{j}\right)=1-k_{j}$, dimana $k_{j}=\sum_{i=1}^{m} G I S\left(r_{i j}\right), j=1,2, \cdots, n$. Selanjutnya akan dikonstruksi menjadi:

$$
\begin{aligned}
\vartheta_{i} & =G I V I F I W A\left(\vartheta_{i 1}, \vartheta_{i 2}, \cdots, \vartheta_{i n}\right) \\
& =\left\langle\left[A_{i}, B_{i}\right],\left[C_{i}, D_{i}\right]\right\rangle,
\end{aligned}
$$

dimana untuk setiap $i=1,2, \cdots, m$, maka

$$
\begin{aligned}
A_{i}= & \left(1-\prod_{j=1}^{n}\left(1-\left(1-c_{i j}\right)^{\lambda}+\left(1-\left(a_{i j}+c_{i j}\right)\right)^{\lambda}\right)^{\omega_{j}}+\prod_{j=1}^{n}\left(1-\left(a_{i j}+c_{i j}\right)\right)^{\lambda \omega_{j}}\right)^{\frac{1}{\lambda}} \\
& -\prod_{j=1}^{n}\left(1-\left(a_{i j}+c_{i j}\right)\right)^{\omega_{j}} ; \\
B_{i}= & \left(1-\prod_{j=1}^{n}\left(1-\left(1-d_{i j}\right)^{\lambda}+\left(1-\left(b_{i j}+d_{i j}\right)\right)^{\lambda}\right)^{\omega_{j}}+\prod_{j=1}^{n}\left(1-\left(b_{i j}+d_{i j}\right)\right)^{\lambda \omega_{j}}\right)^{\frac{1}{\lambda}} \\
& -\prod_{j=1}^{n}\left(1-\left(b_{i j}+d_{i j}\right)\right)^{\omega_{j}} ; \\
C_{i}= & 1-\left(1-\prod_{j=1}^{n}\left(1-\left(1-c_{i j}\right)^{\lambda}+\left(1-\left(a_{i j}+c_{i j}\right)^{\lambda}\right)^{\omega_{j}}+\prod_{j=1}^{n}\left(1-\left(a_{i j}+c_{i j}\right)^{\lambda \omega_{j}}\right)^{\frac{1}{\lambda}} ;\right.\right. \\
D_{i}= & 1-\left(1-\prod_{j=1}^{n}\left(1-\left(1-d_{i j}\right)^{\lambda}+\left(1-\left(b_{i j}+d_{i j}\right)^{\lambda}\right)^{\omega_{j}}+\prod_{j=1}^{n}\left(1-\left(b_{i j}+d_{i j}\right)^{\lambda \omega_{j}}\right)^{\frac{1}{\lambda}} .\right.\right.
\end{aligned}
$$

Seterusnya dihitung dengan menggunakan GIS.

(4) Perluasan dari fungsi skor yang ditingkatkan dan diperumum dengan melibatkan bobot atribut merupakan cara yang tepat untuk menyelesaikan masalah pengambilan keputusan multi-kriteria(MCDM), yaitu masalah untuk pengambilan keputusan seorang nelayan yang ingin beralih profesi menjadi seorang peternak hewan air tawar.

\section{Ucapan Terima kasih}

Penulis mengucapkan terima kasih kepada Ibu Monika Rianti Helmi, M.Si, Ibu Dr. Haripamyu, bapak Zulakmal, M.Si dan Ibu Nova Noliza Bakar, M.Si yang telah memberikan kritikan, saran dan bimbingan sehingga makalah ini dapat diselesaikan dengan baik.

\section{Daftar Pustaka}

[1] Atanassov, K.T. 1986. Intuitionistic fuzzy sets. Fuzzy Sets and Systems. 20: 87 $-96$

[2] Atanassov, K. dan G. Gargov. 1989. Interval valued intuisionistic fuzzy sets. Fuzzy Sets and Systems. 31: 343 - 349

[3] Bai.Z.-Y. 2013. An interval-valued intuitionistic fuzzy TOPSIS method based on an improved score function. Sci. World J . 2013: Article ID 879089 
[4] Garg. H. 2015. Generalized intuitionistic fuzzy multiplicative interactive geometric operators and their application to multiple criteria decision making. Int. J. Mach. Learn. Cybern: $1-18$

[5] Wang. W, Wang. Z. 2008. An approach to multi-attribute interval-valued intuitionistic fuzzy decision making with incomplete weight information. Proceedings of the 15th IEEE International Conference on Fuzzy Systems and Knowledge Discovery. 3: 346 - 350

[6] Xu. Z. 2007. Method for aggregating interval-valued intuitionistic fuzzy information and their application to decision-making. Control Decis. 22: 1179 - 1187

[7] Xu. Z, Chen. J. 2007. Approach to group decision making based on interval valued intuitionistic judgment matrices. Syst. Eng. Theory Pract. 27: $126-133$

[8] Xu. Z.S. 2007. Intuitionistic fuzzy aggregation operators. IEEE Trans. Fuzzy. 15: $1179-1181$

[9] Yu. D. 2015. Intuitionistic fuzzy theory based typhoon disaster evaluation in Zhejiang Province, China: a comparative perspective. Nat. Hazards. 75: $2559-$ 2576

[10] Zadeh. L.A. 1965. Fuzzy sets. Information and Control. 8: $338-353$

[11] Zhao. H, Xu. Z, Ni. M, Liu. S. 2010. Generalized aggregation operators for intuitionistic fuzzy sets. Int. J. Intell 25: $1-30$ 